\title{
REVIEW
}

\section{The 'microflora hypothesis' of allergic diseases}

\author{
M. C. Noverr* and G. B. Huffnagle*† \\ *Department of Internal Medicine, Division of Pulmonary and Critical Care Medicine and $†$ Department of Microbiology and Immunology, University of \\ Michigan Medical School, Ann Arbor, Michigan, USA
}

\begin{abstract}
Summary
Increasingly, epidemiologic and clinical data support the hypothesis that perturbations in the gastrointestinal (GI) microbiota because of antibiotic use and dietary differences in 'industrialized' countries have disrupted the normal microbiota-mediated mechanisms of immunological tolerance in the mucosa, leading to an increase in the incidence of allergic airway disease. The data supporting this 'microflora hypothesis' includes correlations between allergic airway disease and (1) antibiotic use early in life, (2) altered fecal microbiota and (3) dietary changes over the past two decades. Our laboratory has recently demonstrated that mice can develop allergic airway responses to allergens if their endogenous microbiota is altered at the time of first allergen exposure. These experimental and clinical observations are consistent with other studies demonstrating that the endogenous microbiota plays a significant role in shaping the development of the immune system. Data are beginning to accumulate that a 'balanced' microbiota plays a positive role in maintaining mucosal immunologic tolerance long after post-natal development. Other studies have demonstrated that even small volumes delivered to the nasopharynx largely end up in the GI tract, suggesting that airway tolerance and oral tolerance may operate simultaneously. The mechanism of microbiota modulation of host immunity is not known; however, host and microbial oxylipins are one potential set of immunomodulatory molecules that may control mucosal tolerance. The cumulative data are beginning to support the notion that probiotic and prebiotic strategies be considered for patients coming off of antibiotic therapy.
\end{abstract}

\section{Introduction}

In the United States, Canada, United Kingdom, Ireland, New Zealand and Australia, the incidence of allergic airway disease among 13-14-year old children is currently the highest in the world and ranges from $22 \%$ to $32 \%$ [1]. The high incidence in these countries is consistent with a world-wide trend in which the incidence of allergic airway disease in industrialized countries has increased over the past 40 years while remaining stable in developing countries [2]. This recent increase in the asthma rate, coupled with the dichotomy in the incidence of asthma between industrialized and developing countries, suggests that environmental changes are a major factor in the development of asthma [3-5]. Numerous studies have laid the foundation for the hypothesis that a lack of early microbial stimulation (infection or exposure) results in aberrant immune responses to innocuous antigens later in life, i.e. the 'hygiene hypothesis' [6-8]. In addition, other environmental factors such as differences in diet between industrialized vs. developing countries have been noted. This review focuses on an alternative interpretation of the data supporting the 'hygiene hypothesis.' The 'microflora hypothesis' proposes that perturbations in the gastrointestinal (GI)

Correspondence: Gary B. Huffnagle, Department of Internal Medicine, Division of Pulmonary and Critical Care Medicine, University of Michigan Medical School, Ann Arbor, MI 48109-0642, USA.

E-mail: ghuff@umich.edu microbiota because of antibiotic use and dietary differences in 'industrialized' countries have disrupted the normal microbiota-mediated mechanisms of immunological tolerance in the mucosa, which has led to an increase in the incidence of allergic airway disease.

There is a significant amount of epidemiologic and clinical data supporting this altered microflora hypothesis. These include correlations between allergic airway disease and (1) antibiotic use early in life, (2) altered fecal microbiota and (3) dietary changes over the past two decades. Our laboratory has recently demonstrated that mice can develop allergic airway responses to allergens if their endogenous microbiota is altered at the time of first allergen exposure [9, 10]. In contrast, mice with normal microbiota do not develop allergic responses upon airway exposure to the allergens. These experimental and clinical observations are consistent with other studies demonstrating that the endogenous microbiota plays a significant role in shaping the development of the immune system [11-18]. There is currently a significant level of interest in the role of the endogenous microbiota as initiators of inflammatory diseases such as inflammatory bowel disease and arthritis [19, 20] and in how the immune system adapts to the presence of the microbiota in the GI tract during development [21-23]. However, we believe that it is now becoming clear that a 'balanced' microbiota plays a positive role in maintaining mucosal immunologic tolerance long after post-natal development, similar to ideas proposed by Rook and Brunet [24]. Thus, we predict that elements that 
disrupt the dynamics of the microbiota, such as antibiotics and diet, will disrupt mucosal tolerance.

\section{Regulation of mucosal tolerance}

Repeated antigen exposure in the airways does not result in enhanced reactivity; rather, it leads to decreasing responsiveness and the development of immunologic tolerance to the antigen [25-28]. Regulatory T cells (Treg) are the mediators of immunological tolerance and these cells possess antiinflammatory capabilities (Fig. 1). Treg comprise a diverse group of cells that, even in small numbers, can suppress antigen-specific responses (largely via IL-10 and/or transforming growth factor- $\beta$ ). The type and maturation state of the antigen-presenting cell appears to play the most significant role in the development of Treg. Dendritic cells (DC) are the antigen-presenting cell primarily responsible for the antigen-specific activation of naïve $\mathrm{T}$ cells. While mature DC (activated by inflammatory signals) induce differentiation of inflammatory $\mathrm{T}$ cells (T helper [Th]1 and Th2), immature DC (absence of inflammatory signals) appear to induce the differentiation of Treg (Fig. 1) [29-31]. Resident DC in the airways are normally exposed to airborne antigens under non-inflammatory conditions that are believed to induce Treg responses to the antigens, thereby limiting $\mathrm{T}$ cell-mediated inflammatory responses. Interestingly, compared with immunogenic proteins, aeroallergens are micro-particulates that contain a number of moieties that are immunogenic and can stimulate inflammatory cytokine production by lung leucocytes when isolated in pure form [32]. However, aeroallergens induce minimal, if any, response in the lungs upon repeated exposure demonstrating that they are subject to tolerigenic mechanisms.

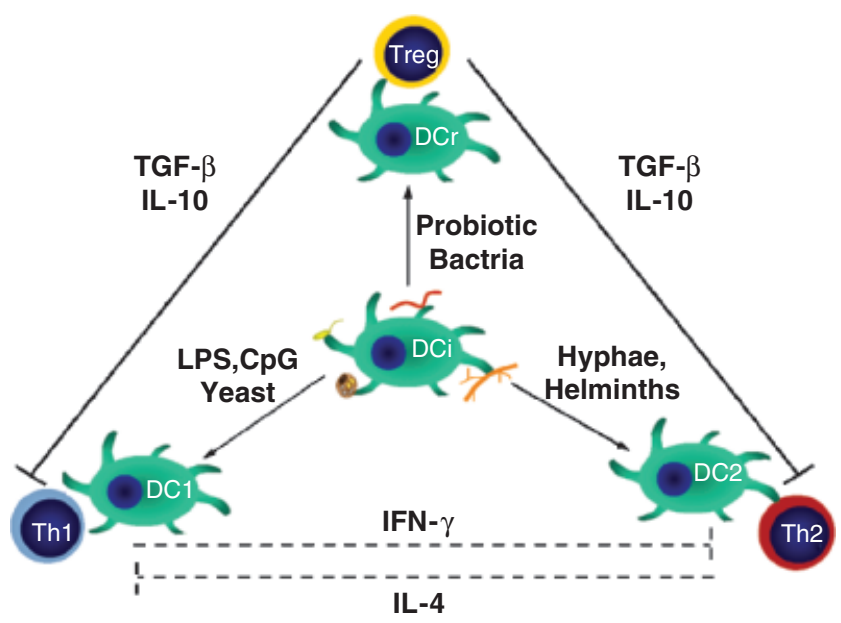

Fig. 1. T cell subset interactions and the role of dendritic cell (DC) maturation in the development of $\mathrm{T}$ cell subsets. Immature dendritic cells (DCi) can mature into regulatory (DCr), type 1 (DC1) and type 2 (DC2) phenotypes depending on the interaction between pathogen recognition receptor (PRR) and Toll-like receptor (TLR) binding to different microbes and microbial products. In addition, DC differentiation is also influenced by cytokines and oxylipins (prostaglandins and leukotrienes) in the local environment. These different DCs promote differentiation of naïve T cells into regulatory (Treg), type 1 (Th1) and type 2 (Th2) T cells, respectively. Treg can dampen both Th1 and Th2 cells by production of transforming growth factor- $\beta$ and IL-10. Th1 and Th2 can counter-regulate each other via cytokine production.
Oral delivery of antigens also leads to the development of antigen-specific immunologic tolerance, a phenomena known as oral tolerance [33-35]. Oral tolerance to an allergen can block responses outside of the GI tract including the allergic response to that allergen in the lungs [36-38]. Similar to airway tolerance, oral tolerance is also mediated by Treg cells $[27,28,34,35]$. The cellular mechanisms underlying oral tolerance are still an arena of intense investigation. Studies have demonstrated that (1) the normal microbiota is required for the generation of oral tolerance as it cannot be generated in germfree mice and (2) conventionalization of germ-free mice with normal microbiota can restore the ability to generate oral tolerance in these mice, indicating that tolerance continues to be regulated by the microbiota long after the post-natal period [11,39].

Induction of oral tolerance has been suggested as a therapeutic strategy for treating asthma [27, 28,34], but does oral tolerance normally play a role in down-regulating immune responses to inhaled allergens? The mucociliary architecture of the nasopharyngeal cavity and upper airways naturally sweeps all inhaled micro-particulates that stick to the mucus lining into the GI tract. Shortly after intranasal inoculation, fluids, particles and microbes introduced into the nasal cavity are largely found in the GI tract [40-42]. In mice, intranasal inoculation of a volume as small as $2.5 \mu \mathrm{L}$ still largely ends up in the GI tract [41]. Thus, inhaled microparticulates (which comprise the vast majority of aeroallergens) are also swallowed. Therefore, we propose that oral tolerance and airway tolerance are tightly linked and the GI tract acts as a 'sensor' for the development of tolerance to inhaled antigens. We propose that this 'sensor' system can be modified by genetics (affecting innate immune cells) but to an even greater extent by microbiota perturbations exerted by antibiotics and diet (Fig. 2).

\section{Establishment and dynamics of the gastrointestinal microbiota}

The GI tract of infants is sterile at birth but colonization begins upon delivery. GI colonization involves a succession of microbial populations waxing and waning as the diet changes and the host develops [43, 44]. Major factors affecting the nature of the early microbial populations are vaginal delivery vs. caesarian delivery, antibiotic use in the mother and bottlefeeding vs. breastfeeding. By adulthood, the microbial community generally stabilizes and is composed of both permanent members and transient colonizers, which are briefly introduced from an exogenous source. Both prokaryotic and eukaryotic microbes are present although bacterial species predominate. The majority of the bacterial species are strict anaerobes $(97 \%$ ), while only $3 \%$ are aerobic (facultative anaerobes). While an estimated $30-40$ species predominate within the adult GI tract, the microbiota is composed of 400 1000 species, including approximately 60\% unculturable species. The composition of the microbiota differs not only along the length of the GI tract, but also cross-sectionally, with different populations inhabiting the GI mucosa and lumen. The most common anaerobic genera in terms of concentration within the GI tract are Bacteroides, Bifidobacterium, Eubacterium, Fusobacterium, Clostridium and Lactobacillus. Among the facultative anaerobes are the 


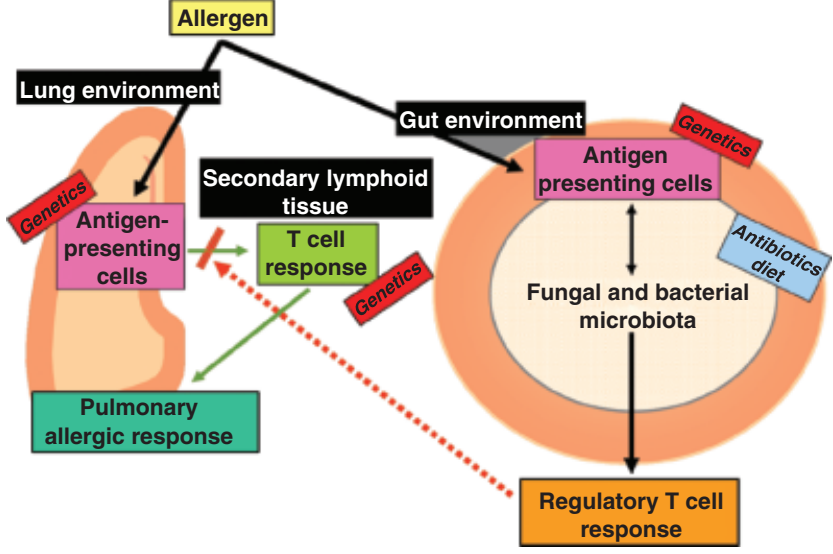

Fig. 2. Model for the regulation of pulmonary allergic responses by the microbiota and gastrointestinal (GI) immune responses. Inhaled aeroallergens are picked up by antigen-presenting cells in the lungs such as resident dendritic cells. The allergen can stimulate dendritic cell (DC) maturation (see Fig. 1) that can promote the development of allergen-specific T cells in the secondary lymphoid organs. These allergen-specific T cells are then recruited into the lungs where, upon encounter with allergen laden antigenpresenting cells, they drive the initial phases of the pathophysiology of the allergic response. Regulatory $\mathrm{T}$ cell (Treg) networks are necessary to prevent the development of this over-exuberant allergic $T$ cell response in the airways. Inhaled aeroallergens are also swallowed because the anatomy of the sinuses and upper airways is designed to trap environmental microparticulates in the mucus layer and then "sweep" them into the throat where they are swallowed. Ingested allergens are then processed by antigen-presenting cells (DC) in the Gl tract. In the anti-inflammatory environment of a healthy GI tract, these $D C$ become regulatory $D C$ (DCr) and promote the development of a Treg response to the allergen. The microbiota plays a key role in signaling for this anti-inflammatory environment and disruption of the normal balance, including increased yeast growth, prevent the development of the Treg response to the allergen. One potential set of signal molecules produced by the host and microbes in the Gl tract are oxylipins. Antibiotics and diet will alter the microbiota balance while host genetics could modulate the response by altering the innate recognition response.

Gram-negative enteric bacteria (Escherichia coli and Salmonella spp.), the Gram-positive cocci (Enterococcus, Staphylococcus and Streptococcus) and fungal species (predominantly Candida albicans). Control of the microbiota populations occurs at the levels of microbe-microbe interactions (competitive exclusion), metabolic competition, host factors and host defenses such as IgA and defensin production [21-23]. As described below, antibiotics and diet can dramatically affect the stability of the microbiota populations.

\section{The association between altered microbiota and allergic disease}

Numerous studies indicate that the GI microbiota is different in atopic vs. non-atopic individuals and in industrialized vs. developing countries [45-51]. Sweden has a high incidence of allergic disease while Estonia has a low incidence. In a series of studies, it was shown that allergic children from either country have similar microbiota composition but the composition differs from non-atopic children. Atopy was associated with increased levels of aerobic microbes and decreased levels of anaerobic microbes, particularly lactobacilli, in fecal samples [45]. In a prospective study, it was noted that infants that developed allergies harbored decreased levels of Bifidobacteria and Enterococcus species but had increased levels of Clostridium species [46]. This is consistent with reports of decreased levels of bifidobacteria and Gram- positive organisms among the aerobic populations in infants with atopic eczema [49]. Individuals living an anthroposophic lifestyle abstain from antibiotic use and ingest fermented foods containing probiotic organisms [52]. Studies on this population of individuals also noted a decreased incidence of atopy compared with the surrounding community and fecal samples contained higher levels of lactic acid bacteria. As discussed below, antibiotic use and dietary differences, such as an increased proportion of refined foods in the diet and differences in fat intake, likely play a role in GI microbiota differences between industrialized and developing countries.

\section{Role of antibiotics in microbiota dynamics and allergic responses}

The major effects of antibiotic treatment on the microbiota are the direct effect of killing a large proportion of the microbiota and the indirect effect of decreasing colonization resistance within the GI tract. Colonization resistance is a multi-faceted mechanism whereby obligate anaerobic microbiota inhibit the overgrowth of potentially harmful exogenous or endogenous microbes. The end result of a reduction in colonization resistance can either be clinically asymptomatic (leading only to an imbalance in the microbiota), localized symptomatic (e.g. diarrhea) or systemic symptomatic (disseminated infection) [53]. In humans, yeast ( $C$. albicans) infections of mucosal sites are one of the most common side effects of antibiotic therapy [53-57]. The ability of the bacterial microbiota to control or prevent $C$. albicans colonization is because of both competitive exclusion of favored niches and by production of growth-altering metabolites such as short chain fatty acids [58-62]. Thus, control of $C$. albicans by the normal microbiota (especially the probiotic species) is very important. Interestingly, changes in the microbiota populations can persist months after cessation antibiotic therapy and can result in long-term decreases in beneficial anaerobic organisms (Bifidobacterium, Lactobacillus, Bacteroides) and increases in potentially harmful microbes (Gram-negative aerobic enteric bacteria, the anaerobe Clostridium dificile and the yeast C. albicans) [55, 63-70].

Two lines of evidence support the concept that antibiotic use can be a major underlying factor in the development of allergic responses. The first are epidemiologic studies. A number of studies have identified a correlation between early antibiotic use in children and the subsequent development of allergy/asthma [71-74]. Other reports have identified a link between multiple ear infections early in childhood (which are treated with multiple courses of antibiotics) and the subsequent development of asthma [75]. Studies have also compared children of families with an anthroposophic lifestyle to children in neighbouring areas. Rates of allergy among anthroposophic children are also significantly lower and there is a correlation between the number of characteristic features of an anthroposophic lifestyle and decreasing risk of developing allergies [52]. Several features of the anthroposophic lifestyle are likely involved in promoting decreased rates of atopy (including a diet high in probioticsfermented foods and restrictive use of vaccines, anti-pyretics and antibiotics) [76]. However, a study investigating anthroposophic children revealed that the use of antibiotic early in life was significantly associated with development of asthma 
[74]. This indicates that antibiotic use within a cohort of children with similar lifestyles predisposes towards atopy. The second line of evidence is derived from national trends of antibiotic use vs. incidence of allergic disease in industrialized (high atopy, high antibiotic use) vs. developing countries (low atopy, low antibiotic use) [3-5]. While it is recognized that other interpretations exist for the correlative data described above, they are consistent with the hypothesis that antibiotic use may predispose an individual to developing allergic airway disease. Within families leading similar lifestyles and eating similar diets, there can exist atopic and non-atopic family members. It is therefore important to remember that genetics play an important role in determining whether atopic disease develops. However, what may be occurring is that environmental factors such as antibiotic use and diet (and subsequent effects on the GI microbiota) might work to uncover these genetic susceptibilities.

\section{Role of the diet in microbiota dynamics and allergic responses}

A significant amount of research effort was invested during the early 20th century in characterizing the effect of diet on the microbiota. This interest was in large part inspired by Eli Metchnikoff, who wrote extensively on the benefits of probiotic microbes in health. Some early experiments on the rodent microbiota demonstrated that it changed rapidly upon altering the diet [77, 78]. Perhaps even more relevant to the current health issues were later studies demonstrating that rodents fed an enriched bread diet exhibited a significantly delayed recovery of the microbiota ratios following antibiotic treatment compared to rodents fed a standard diet [78]. Prebiotics are food components that promote the growth of beneficial bacteria. Examples are prebiotic carbohydrates such as inulin and oligofructose, which stimulate growth of Bifidobacteria in the GI tract. In contrast, the simple sugar fructose stimulates growth of coliform and aerobic organisms in the GI tract [79]. These are a few of the experiments demonstrating that the composition of the host's diet plays a significant role in modulating species composition of the microbiota, as different species grow better on different substrates, which in turn can alter microbe-microbe interactions.

The role of diet in increasing or decreasing the incidence of allergic airway disease has been noted in a number of studies [80-84]. While antibiotic use in the Mediterranean countries of Spain, France, Italy and Greece is not necessarily different than that in the UK, Ireland or Australia, the asthma rates noted in the 1998 International Study of Asthma and Allergies in Childhood (ISAAC) report indicated that the incidence of asthma in these 'Mediterranean Diet' countries is significantly lower (Fig. 3) [1]. Significant attention has been paid to the role of dietary metabolites in direct immune system interactions during allergic responses [80, 81], but the diet also has a significant affect on the composition of the microbiota.

The role of fatty acids in allergic airway disease is not understood. There is a rough association between national polyunsaturated vegetable oil consumption and corresponding national incidence of atopy and asthma [82]. Another study of 10 European countries investigated the association

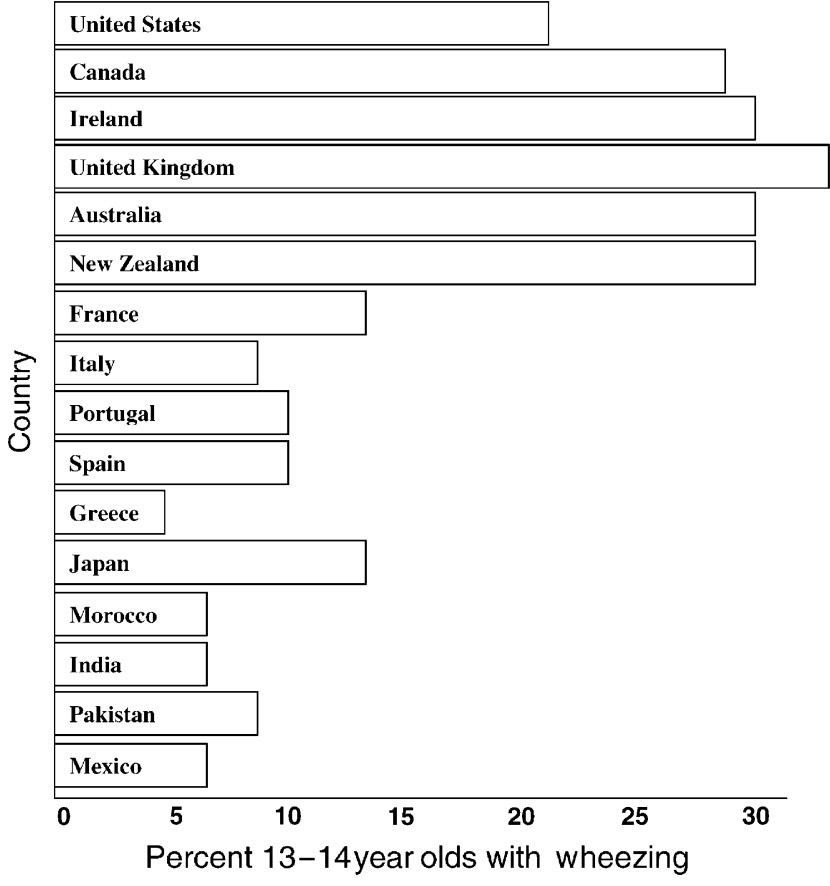

Fig. 3. Incidence of asthma in 13-14-year olds in selected countries around the world. The graph is based upon data from the 1998 International Study of Asthma and Allergies in Childhood (ISAAC) [1]. This graph highlights the lower incidence among Western European countries that follow a Mediterranean Diet.

between dietary trans-fatty acids and the prevalence of childhood asthma and allergies. There was a positive association between dietary trans fatty acids (expressed as percent of energy intake) and the prevalence of asthma, allergic rhinoconjunctivitis and atopic eczema [84]. Another example is a study of dietary fat intake vs. asthma in 478 men, 68 years of age, who were randomly selected from all the men born in Malmo, Sweden in 1914. The study concluded that men with asthma had a significantly higher intake of fat than men without asthma [85]. Generally speaking, these studies and others, discuss the possible role of dietary fats as substrates and modulators of leukotriene and prostaglandin production that would, in turn, augment allergic airway responses.

While dietary fatty acids may directly modify host responses, dietary fatty acid intake also plays a significant role in shaping the population dynamics of the microbiota. For example, a number of strictly anaerobic bacteria have strict requirements for long-chain fatty acids [86]. Thus, changes in dietary fats can alter one or more species of GI microbes, which in turn, can alter the numbers of other species of microbes by altering competitive exclusion dynamics. However, the argument continues to be circular in that the GI microbiota also plays a significant role in the metabolism of lipids and sterols, including biohydrogenation of sterols and fatty acids [87-89]. In the end, there is a tight relationship between dietary fat intake and modulation of GI microbiota dynamics. This raises the question of whether an alteration of GI microbiota populations by dietary fats is an underlying component of the dietary fat-asthma association.

An association has also been noted between higher dietary antioxidant intake and lower incidence of allergic airway 
disease [80]. One class of antioxidants contains compounds such as vitamins $\mathrm{C}$ and $\mathrm{E}$. However, another class of compounds includes polyphenols, which are found in high concentration in the skin of raw fruits and vegetables. A study in Italy demonstrated a correlation between high vegetable consumption and lower incidence of asthma [83]. Other studies have demonstrated an association between low fruit and vitamin $\mathrm{C}$ consumption and impaired lung function [80]. When antioxidant supplementation was examined as a preventative therapy pre-natally, differential results were observed. In atopic women, vitamin E supplementation was negatively associated with atopic disease in infants, while vitamin C was positively associated with atopy [90]. However, a separate study found that only vitamin $\mathrm{C}$ consumed as part of the diet (as opposed to a supplement) ended up in breast milk. In this study, results demonstrated that increased levels of vitamin $\mathrm{C}$ in breast milk was associated with a reduced risk of atopy in the infant. Therefore, an antioxidant-rich diet may be provide greater health benefits than antioxidant supplementation.

What is the mechanism underlying a protective effect of dietary antioxidants? One hypothesis is that membrane lipid peroxidation is elevated in the lungs of asthmatics, leading to cellular damage, the development of pathologic changes and hypersensitivity. Dietary antioxidants in the adult diet might protect against cellular oxidant damage [80]. However, many of the plant antioxidants (including polyphenols) belong to a class of compounds collectively called phytoalexins, which are plant host defense molecules produced in response to microbial attack [91]. Many plant polyphenols are potent inhibitors of the growth of a number of bacterial and fungal species and can also alter microbial metabolism. Thus, similar to dietary fatty acids, this raises the possibility that dietary antioxidants also alter the GI microbiota populations as an underlying component of the dietary antioxidant-asthma association.

One final diet-asthma association we wish to touch on is the association between bottle-feeding during infancy and increased risk of developing asthma. It was noted almost a century ago and confirmed in numerous other studies that there are significant differences in the GI microbiota between breastfed and bottle-fed infants [43, 92]. The chief difference between these two feeding regimens is that the microbiota of breastfed infants is composed mainly of lactic acid bacteria, while the microbiota of bottle-fed infants is more diverse, composed of a mixture of anaerobic bacteria as well as aerobic species [43]. Thus, the role of breastfeeding in protecting against atopic disease may also be related to the beneficial effects on the microbiota.

\section{Experimental evidence that altered microbiota can promote the development of allergic airway disease}

Our laboratory has recently developed a mouse model of antibiotic-induced GI microbiota disruption that is accompanied by stable increases in GI enteric bacteria and $C$. albicans levels [9, 10]. Using this model, we have addressed whether microbiota disruption can promote the development of an allergic airway response to mold spore (Aspergillus fumigatus) or ovalbumin (OVA) challenge. These studies utilized immunocompetent mice and did not involve previous
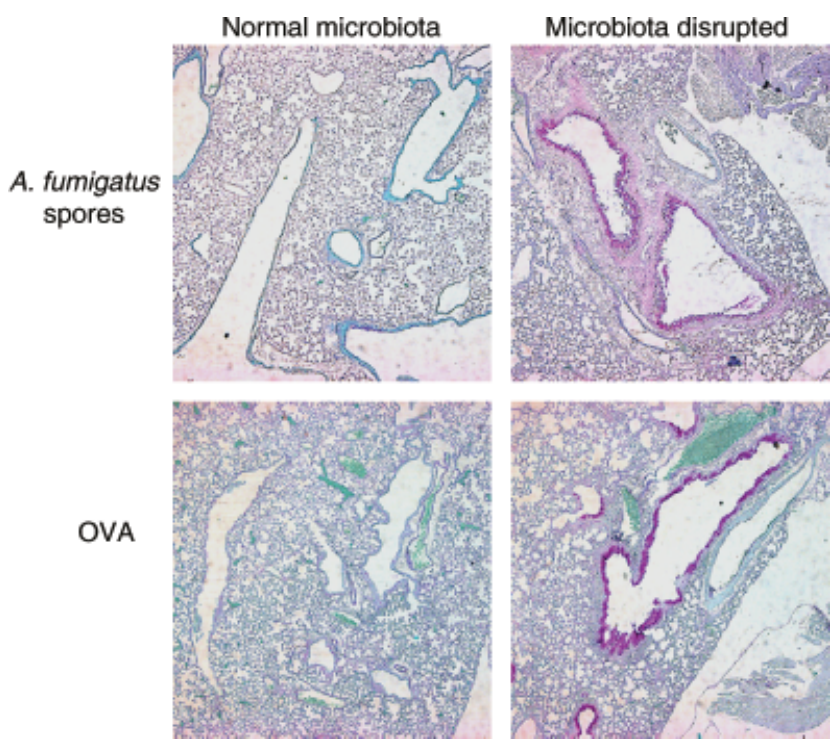

Fig. 4. Effect of gastrointestinal (GI) microbiota disruption on goblet cell metaplasia. One group of mice was treated with antibiotic in the drinking water for 5 days and then colonized in the Gl tract with low levels of the yeast Candida albicans. The second group of mice was left untreated. For both groups of mice, the mice were exposed multiple times intranasally with either mold spores (Aspergillus fumigatus) or ovalbumin, beginning 2 days after cessation of the antibiotics in the first group. Approximately two weeks after the initial exposure, the lungs were harvested, fixed, sectioned and stained with Periodic-Acid Schiff stain to identify mucus-producing goblet cells (pink). Methyl green was used as a counterstain. These photographs illustrate the significant effect of microbiota disruption on promoting an allergic airway response to different types of allergens. Other parameters such as serum immunoglibulin E, pulmonary eosinophils, and IL-5/IL-13 production are also elevated by microbiota disruption during initial allergen challenge $[9,10]$.

systemic antigen priming as is typically used for breaking airway tolerance to these allergens. There was also no evidence of microbial growth in the lungs or inflammation in the GI tract in this model. The parameters measured included pulmonary eosinophilia, total serum immunoglobulin (Ig)E, lung leucocyte IL-5, IL-13 and IFN- $\gamma$, and goblet cell metaplasia. All of these parameters were significantly elevated in the microbiota disrupted mice (Fig. 4). Mice with unaltered microbiota did not develop an allergic response following intranasal challenge with either mold spores or OVA. The response did not develop in IL-13-deficient mice or mice that had been depleted of CD4 $\mathrm{T}$ cells. In addition, vigorous allergic airway responses could be generated in both C57BL/6 and Balb/c mice following microbiota disruption and antigen challenge but not in antigen-challenged 'normal microbiota' $\mathrm{C} 57 \mathrm{BL} / 6$ and $\mathrm{Balb} / \mathrm{c}$ mice. The presence of $C$. albicans in the GI tract was required to break airway tolerance. Thus, these studies demonstrate experimentally that antibiotic treatment, including fungal microbiota growth, can break airway tolerance to an aeroallergen such as mold spores or an experimental non-fungal allergen such as OVA.

Although these studies suggest a connection between the gut microbiota and pulmonary tolerance, the possibility that pulmonary tolerance may be directly affected by subtle changes in the upper respiratory tract microbiota as a result of antibiotic treatment cannot be ruled out. The bronchial mucosa and the GI mucosa use common mechanisms that allow these areas to discriminate among different antigens 
and microbes in order to determine whether a tolerogenic or inflammatory response should follow $[93,94]$. A recent study demonstrated that prior pulmonary viral influenza infection actually enhanced later allergen specific asthma in mice [95]. Pulmonary DCs isolated from lung after viral clearance were able to confer this allergic disease to recipient mice, indicating that similar mechanisms for maintenance and disruption of mucosal tolerance exist in the respiratory and GI tracts. The relative importance of the respiratory mucosa and the GI mucosa in controlling tolerance to inhaled/swallowed antigens remains to be determined.

What are the possible mechanisms underlying the break in tolerance during microbiota disruption?

This question clearly lies at the heart of the 'microflora hypothesis' of allergic airway disease. The most likely mechanism involves a break in the ability to generate Treg cells. Recall that antigens acquired by DCs in the absence of inflammation or in an anti-inflammatory environment such as a microbiota-balanced healthy GI tract preferentially stimulate the generation of Treg cells that can be recruited to the airways. Thus, it is our hypothesis at this point that microbiota disruption involves a disruption of this antiinflammatory environment of the GI tract, where inhaled/ swallowed micro-particulate antigens (aeroallergens) are acquired by DCs. The allergen-primed DCs then undergo maturation because of the stimulatory nature of the aeroallergen and a Treg response is not generated. In the lungs, the aeroallergen stimulates a mix of an inflammatory and a Th2 response, which is normally down-regulated by the Treg response, but is now left unchecked and develops into an allergic response in the airways.

Two possible mechanisms that may play a role in disrupting the anti-inflammatory environment of the GI tract are decreased short-chain fatty acid production by probiotic bacteria and increased oxylipin production by yeast. Shortchain fatty acids, such as butyric acid, are by-products of anaerobic fermentation by the normal probiotic members of the microbiota and these fatty acids possess anti-inflammatory activity [96-100]. Short-chain fatty acids can also inhibit C. albicans hyphal transformation, an important step in persistence of $C$. albicans on mucosal surfaces [58, 59]. Oxylipins are oxidized fatty acid metabolites that are produced by $C$. albicans and other fungi [101-103]. These oxylipins include leukotriene-like and prostaglandin-like molecules that can be synthesized de novo or via conversion of exogenous arachidonic acid by the yeast. Host-derived prostaglandins and leukotrienes are potent immunomodulatory molecules that can modulate innate and adaptive immune responses. Microbe-derived prostaglandin-like molecules are active on mammalian cells and can alter dendritic cell migration and biology [101]. The hypothesis of our current studies builds upon these observations and is investigating whether production of oxylipins is required for the immunomodulatory activity of $C$. albicans. Other potential mechanisms exist. However, it is intriguing that the fatty acid metabolite leukotriene $\mathrm{C}_{4}\left(\mathrm{LTC}_{4}\right)$ is required for dendritic cell movement from tissues to the lymph nodes, $\mathrm{LTC}_{4}$ is secreted from cells via the action of a multi-drug resistance pump, and knockout mice deficient in one of the multi-drug resistance pumps spontaneously develop colitis, a disease believed to be caused by a deficient Treg response [104-106]. Thus, fatty acid metabolites from the host and the microbiota, which would be influenced by dietary fatty acid content, may play a critical role in maintaining the antiinflammatory environment of the GI tract necessary for mucosal tolerance.

\section{Probiotic therapy as treatment for atopic diseases}

Probiotic supplementation has been practiced for over a century and has resulted in a litany of anecdotal evidence that suggests a connection to improved health. Probiotics are defined as live microbial supplements that exert a beneficial effect on health and are non-pathogenic. There is also some evidence that oral delivery of heat-killed saprophytic soil mycobacteria can down-regulate symptoms of allergic inflammation in animal models [107]. Current investigations of probiotic therapy provide statistical evidence that live microbial supplementation can produce positive results in both therapeutic and preventative ways. In regards to atopic diseases, the majority of human trials have focused on neonatal or infant subjects. In a randomized placebocontrolled study, Lactobacillus casei $G G$ was effective in prevention of atopic eczema in children at-risk (one or more first-degree relatives with allergic disease) [108, 109]. Atopic eczema is often the earliest manifestation of subsequent allergic diseases in infants and children; therefore, a follow-up of this study was performed 2 years later. Interestingly, children who received prior probiotic supplementation exhibited protection from other atopic diseases that extended beyond infancy [108, 109]. A separate study demonstrated that the protection provided by early probiotic therapy also extends into adulthood [110]. In addition to post-natal therapy, pre-natal probiotic supplementation in pregnant women with a history of atopic disease reduced rates of atopy in their infants [111]. Other studies examined the ability of probiotics to treat atopic disease in infants. In these studies, probiotic supplementation decreased severity of atopic eczema, atopic dermatitis and food allergy compared with controls [112-117]. While these studies point to a role for modulation of the microbiota in children and infants as a preventative or therapeutic strategy against allergic disease, very little effort has been made to examine the role of probiotics in management allergy in adults. Among studies examining adults, probiotic supplementation resulted in a decrease in numbers of CD34 ${ }^{+}$stem cell levels (an indicator for systemic allergic inflammation) [118]. In asthma patients, supplementation with yogurt containing probiotic Lactobacillus resulted in decreased pro-inflammatory cytokine levels and eosinophilia; however, clinical parameters of asthma were unchanged [119]. These results underscore the need for further clinical trials of probiotic and prebiotic therapy in adults with allergic disease.

\section{Future perspectives}

Allergic airway disease is a continuum of pathophysiologic changes in the host. It ranges from mild inflammation to severe inflammation and will ultimately result in structural changes in the airways and in the biology of the airway 
smooth muscles and epithelium. It is clear from numerous studies that respiratory infection, airborne irritants, the nature of the allergen, exposure rates and genetics all influence the development and manifestation of asthma. However, it is our hypothesis that disruption of the normal microbiota breaks airway tolerance to aeroallergens (nonpathogenic micro-particulates that possess antigenic/inflammatory properties). Once tolerance is disrupted, other factors play a role in either promoting or preventing the development of airway hypersensitivity (genetics, infection). One of the difficulties in family association studies is that non-genetic effects are often difficult to discern from genetic effects. Diet, co-housing, physical interaction, non-life threatening communicable diseases and health practices are significantly more common between members of a family than between members of different families. These factors also influence an individual's microbiota. Thus, generating direct proof for the 'microflora hypothesis' of allergic disease will rely largely upon experimental animal models and well-controlled human intervention studies such as are now being proposed and carried out with probiotic therapies in children. The accumulating evidence also suggests that the medical establishment should more seriously consider the role of diet in chronic disease, think seriously about prescribing long-term antibiotics for non-life threatening conditions and also consider probiotic and prebiotic strategies for patients coming off of antibiotic therapy.

\section{Acknowledgements}

The authors have been supported by funding from the National Institute of Allergy and Infectious Diseases, the National Heart, Lung, Blood Institute and the BurroughsWellcome Fund.

\section{References}

1 Worldwide variations in the prevalence of asthma symptoms: the International Study of Asthma and Allergies in Childhood (ISAAC). Eur Respir J 1998; 12:315-35.

2 Mannino DM, Homa DM, Pertowski CA et al. Surveillance for asthma - United States, 1960-1995. MMWR CDC Surveill Summ 1998; 47:1-27.

3 Beasley R, Crane J, Lai CK, Pearce N. Prevalence and etiology of asthma. J Allergy Clin Immunol 2000; 105:S466-72.

4 Burney PG, Luczynska C, Chinn S, Jarvis D. The European Community Respiratory Health Survey. Eur Respir J 1994; 7:954-60.

5 Asher MI, Keil U, Anderson HR et al. International Study of Asthma and Allergies in Childhood (ISAAC): rationale and methods. Eur Respir J 1995; 8:483-91.

6 Strachan DP. Hay fever, hygiene, and household size. BMJ 1989; 299:1259-60.

7 Umetsu DT, McIntire JJ, Akbari O, Macaubas C, DeKruyff RH. Asthma: an epidemic of dysregulated immunity. Nat Immunol 2002; 3:715-20.

8 Wills-Karp M, Santeliz J, Karp CL. The germless theory of allergic disease: revisiting the hygiene hypothesis. Nat Rev Immunol 2001; 1:69-75.

9 Noverr MC, Falkowski NR, McDonald RA, Huffnagle GB. The development of allergic airway disease in mice following antibiotic therapy and fungal microbiota increase: role of host genetics, antigen and IL-13. Infect Immun 2005; 73:30-8.

10 Noverr MC, Noggle RM, Toews GB, Huffnagle GB. Role of antibiotics and fungal microbiota in driving pulmonary allergic responses. Infect Immun 2004; 72:4996-5003.

11 Maeda Y, Noda S, Tanaka K et al. The failure of oral tolerance induction is functionally coupled to the absence of $\mathrm{T}$ cells in Peyer's patches under germfree conditions. Immunobiology 2001; 204:442-57.

12 Cooper MD, Kincade PW, Bockman DE, Lawton AR. Origin, distribution and differentiation of IgA-producing cells. Adv Exp Med Biol 1974; 45:13-22.

13 Yamanaka T, Helgeland L, Farstad IN, Fukushima H, Midtvedt T, Brandtzaeg P. Microbial colonization drives lymphocyte accumulation and differentiation in the follicle-associated epithelium of Peyer's patches. J Immunol 2003; 170:816-22.

14 Bauer H, Horowitz RE, Levenson SM, Popper H. The response of the lymphatic tissue to the microbial flora. Studies on germfree mice. Am J Pathol 1963; 42:471-83.

15 Lefrancois L, Goodman T. In vivo modulation of cytolytic activity and Thy-1 expression in TCR-gamma delta+intraepithelial lymphocytes. Science 1989; 243:1716-8.

16 Bandeira A, Mota-Santos T, Itohara S et al. Localization of gamma/delta T cells to the intestinal epithelium is independent of normal microbial colonization. J Exp Med 1990; 172: 239-44.

17 Bos NA, Cebra JJ, Kroese FG. B-1 cells and the intestinal microflora. Curr Top Microbiol Immunol 2000; 252:211-20.

18 Umesaki Y, Setoyama H. Structure of the intestinal flora responsible for development of the gut immune system in a rodent model. Microbes Infect 2000; 2:1343-51.

19 Sellon RK, Tonkonogy S, Schultz M et al. Resident enteric bacteria are necessary for development of spontaneous colitis and immune system activation in interleukin-10-deficient mice. Infect Immun 1998; 66:5224-31.

20 Taurog JD, Richardson JA, Croft JT et al. The germfree state prevents development of gut and joint inflammatory disease in HLA-B27 transgenic rats. J Exp Med 1994; 180:2359-64.

$21 \mathrm{Xu}$ J, Chiang HC, Bjursell MK, Gordon JI. Message from a human gut symbiont: sensitivity is a prerequisite for sharing. Trends Microbiol 2004; 12:21-8.

22 Macpherson AJ, Harris NL. Interactions between commensal intestinal bacteria and the immune system. Nat Rev Immunol 2004; 4:478-85.

23 Hooper LV. Bacterial contributions to mammalian gut development. Trends Microbiol 2004; 12:129-34.

24 Rook GA, Brunet LR. Old friends for breakfast. Clin Exp Allergy $2005 ; 35: 841-2$.

25 Hall G, Houghton CG, Rahbek JU, Lamb JR, Jarman ER. Suppression of allergen reactive Th2 mediated responses and pulmonary eosinophilia by intranasal administration of an immunodominant peptide is linked to IL-10 production. Vaccine 2003; 21:549-61.

26 Takabayashi K, Libet L, Chisholm D, Zubeldia J, Horner AA. Intranasal immunotherapy is more effective than intradermal immunotherapy for the induction of airway allergen tolerance in Th2-sensitized mice. J Immunol 2003; 170:3898-905.

27 Akbari O, Stock P, DeKruyff RH, Umetsu DT. Role of regulatory $\mathrm{T}$ cells in allergy and asthma. Curr Opin Immunol 2003; 15:627-33.

28 Herrick CA, Bottomly K. To respond or not to respond: T cells in allergic asthma. Nat Rev Immunol 2003; 3:405-12.

29 Steinman RM, Turley S, Mellman I, Inaba K. The induction of tolerance by dendritic cells that have captured apoptotic cells. J Exp Med 2000; 191:411-6.

30 Jonuleit H, Schmitt E, Schuler G, Knop J, Enk AH. Induction of interleukin 10-producing, nonproliferating CD4(+) T cells with 
regulatory properties by repetitive stimulation with allogeneic immature human dendritic cells. J Exp Med 2000; 192:1213-22.

31 Jonuleit H, Schmitt E, Steinbrink K, Enk AH. Dendritic cells as a tool to induce anergic and regulatory $\mathrm{T}$ cells. Trends Immunol 2001; 22:394-400.

32 Kheradmand F, Kiss A, Xu J, Lee SH, Kolattukudy PE, Corry DB. A protease-activated pathway underlying Th cell type 2 activation and allergic lung disease. J Immunol 2002; 169:5904-11.

33 Alpan O. Oral tolerance and gut-oriented immune response to dietary proteins. Curr Allergy Asthma Rep 2001; 1:572-7.

34 Smith KM, Eaton AD, Finlayson LM, Garside P. Oral tolerance. Am J Respir Crit Care Med 2000; 162:S175-8.

35 Weiner HL. Oral tolerance: immune mechanisms and the generation of Th3-type TGF-beta-secreting regulatory cells. Microbes Infect 2001; 3:947-54

36 Russo M, Jancar S, Pereira de Siqueira AL et al. Prevention of lung eosinophilic inflammation by oral tolerance. Immunol Lett 1998; 61:15-23.

37 Chung Y, Cho J, Chang YS, Cho SH, Kang CY. Preventive and therapeutic effects of oral tolerance in a murine model of asthma. Immunobiology 2002; 206:408-23.

38 Russo M, Nahori MA, Lefort J et al. Suppression of asthma-like responses in different mouse strains by oral tolerance. Am $\mathrm{J}$ Respir Cell Mol Biol 2001; 24:518-26.

39 Sudo N, Sawamura S, Tanaka K, Aiba Y, Kubo C, Koga Y. The requirement of intestinal bacterial flora for the development of an IgE production system fully susceptible to oral tolerance induction. J Immunol 1997; 159:1739-45.

40 Southam DS, Dolovich M, O'Byrne PM, Inman MD. Distribution of intranasal instillations in mice: effects of volume, time, body position, and anesthesia. Am J Physiol Lung Cell Mol Physiol 2002; 282:L833-9.

41 Pickett TE, Pasetti MF, Galen JE, Sztein MB, Levine MM. In vivo characterization of the murine intranasal model for assessing the immunogenicity of attenuated Salmonella enterica serovar Typhi strains as live mucosal vaccines and as live vectors. Infect Immun 2000; 68:205-13.

42 Eyles JE, Spiers ID, Williamson ED, Alpar HO. Tissue distribution of radioactivity following intranasal administration of radioactive microspheres. J Pharm Pharmacol 2001; 53:601-7.

43 Fanaro S, Chierici R, Guerrini P, Vigi V. Intestinal microflora in early infancy: composition and development. Acta Paediatr 2003; 91 (Suppl.):48-55.

44 Tannock GW. Normal microflora: an introduction to microbes inhabiting the human body. London: Chapman \& Hall, 1995.

45 Bjorksten B, Naaber P, Sepp E, Mikelsaar M. The intestinal microflora in allergic Estonian and Swedish 2-year-old children. Clin Exp Allergy 1999; 29:342-6.

46 Bjorksten B, Sepp E, Julge K, Voor T, Mikelsaar M. Allergy development and the intestinal microflora during the first year of life. J Allergy Clin Immunol 2001; 108:516-20.

47 Bottcher MF, Nordin EK, Sandin A, Midtvedt T, Bjorksten B. Microflora-associated characteristics in faeces from allergic and nonallergic infants. Clin Exp Allergy 2000; 30:1590-6.

48 Kalliomaki M, Kirjavainen P, Eerola E, Kero P, Salminen S, Isolauri E. Distinct patterns of neonatal gut microflora in infants in whom atopy was and was not developing. J Allergy Clin Immunol 2001; 107:129-34.

49 Kirjavainen PV, Apostolou E, Arvola T, Salminen SJ, Gibson GR, Isolauri E. Characterizing the composition of intestinal microflora as a prospective treatment target in infant allergic disease. FEMS Immunol Med Microbiol 2001; 32:1-7.

50 Kirjavainen PV, Arvola T, Salminen SJ, Isolauri E. Aberrant composition of gut microbiota of allergic infants: a target of bifidobacterial therapy at weaning? Gut 2002; 51:51-5.
51 Adlerberth I, Carlsson B, de Man P et al. Intestinal colonization with Enterobacteriaceae in Pakistani and Swedish hospitaldelivered infants. Acta Paediatr Scand 1991; 80:602-10.

52 Alm JS, Swartz J, Lilja G, Scheynius A, Pershagen G. Atopy in children of families with an anthroposophic lifestyle. Lancet 1999; 353:1485-8.

53 Sullivan A, Edlund C, Nord CE. Effect of antimicrobial agents on the ecological balance of human microflora. Lancet Infect Dis 2001; 1:101-14.

54 Giuliano M, Barza M, Jacobus NV, Gorbach SL. Effect of broadspectrum parenteral antibiotics on composition of intestinal microflora of humans. Antimicrob Agents Chemother 1987; 31:202-6.

55 Samonis G, Gikas A, Anaissie EJ et al. Prospective evaluation of effects of broad-spectrum antibiotics on gastrointestinal yeast colonization of humans. Antimicrob Agents Chemother 1993; 37:51-3.

56 Huang MY, Wang JH. Impact of antibiotic use on fungus colonization in patients hospitalized due to fever. J Microbiol Immunol Infect 2003; 36:123-8.

57 Maraki S, Margioris AN, Orfanoudaki E et al. Effects of doxycycline, metronidazole and their combination on Candida species colonization of the human oropharynx, intestinal lumen and vagina. J Chemother 2003; 15:369-73.

58 Hoberg KA, Cihlar RL, Calderone RA. Inhibitory effect of cerulenin and sodium butyrate on germination of Candida albicans. Antimicrob Agents Chemother 1983; 24:401-8.

59 Noverr MC, Huffnagle GB. Regulation of Candida albicans morphogenesis by fatty acid metabolites. Infect Immun 2004; 72:6206-10.

60 Sjogren J, Magnusson J, Broberg A, Schnurer J, Kenne L. Antifungal 3-hydroxy fatty acids from Lactobacillus plantarum milab 14. Appl Environ Microbiol 2003; 69:7554-7.

61 Magnusson J, Strom K, Roos S, Sjogren J, Schnurer J. Broad and complex antifungal activity among environmental isolates of lactic acid bacteria. FEMS Microbiol Lett 2003; 219: 129-35.

62 Hogan DA, Vik A, Kolter R. A Pseudomonas aeruginosa quorum-sensing molecule influences Candida albicans morphology. Mol Microbiol 2004; 54:1212-23.

63 Orrhage K, Nord CE. Bifidobacteria and lactobacilli in human health. Drugs Exp Clin Res 2000; 26:95-111.

64 Sjovall J, Huitfeldt B, Magni L, Nord CE. Effect of beta-lactam prodrugs on human intestinal microflora. Scand J Infect Dis Suppl 1986; 49:73-84.

65 Lidbeck A, Nord CE. Lactobacilli and the normal human anaerobic microflora. Clin Infect Dis 1993; 16 (Suppl. 4): S181-7.

66 van der Waaij D. The ecology of the human intestine and its consequences for overgrowth by pathogens such as Clostridium difficile. Annu Rev Microbiol 1989; 43:69-87.

67 Payne S, Gibson G, Wynne A, Hudspith B, Brostoff J, Tuohy K. In vitro studies on colonization resistance of the human gut microbiota to Candida albicans and the effects of tetracycline and Lactobacillus plantarum LPK. Curr Issues Intest Microbiol 2003; 4:1-8.

68 Guggenbichler JP, Kofler J, Allerberger F. The influence of thirdgeneration cephalosporins on the aerobic intestinal flora. Infection 1985; 13 (Suppl. 1):S137-9.

69 Mulligan ME, Citron DM, McNamara BT, Finegold SM. Impact of cefoperazone therapy on fecal flora. Antimicrob Agents Chemother 1982; 22:226-30.

70 Tannock GW. Analysis of the intestinal microflora using molecular methods. Eur J Clin Nutr 2002; 56 (Suppl. 4):S44-9.

71 McKeever TM, Lewis SA, Smith C et al. Early exposure to infections and antibiotics and the incidence of allergic disease: a birth cohort study with the West Midlands 
General Practice Research Database. J Allergy Clin Immunol 2002; 109:43-50.

72 Farooqi IS, Hopkin JM. Early childhood infection and atopic disorder. Thorax 1998; 53:927-32.

73 Droste JH, Wieringa MH, Weyler JJ, Nelen VJ, Vermeire PA, Van Bever HP. Does the use of antibiotics in early childhood increase the risk of asthma and allergic disease? Clin Exp Allergy 2000; 30:1547-53.

74 Wickens K, Pearce N, Crane J, Beasley R. Antibiotic use in early childhood and the development of asthma. Clin Exp Allergy 1999; 29:766-71

75 Eldeirawi K, Persky VW. History of ear infections and prevalence of asthma in a national sample of children aged 2 to 11 years: the Third National Health and Nutrition Examination Survey, 1988 to 1994. Chest 2004; 125:1685-92.

76 Alm JS, Swartz J, Bjorksten B et al. An anthroposophic lifestyle and intestinal microflora in infancy. Pediatr Allergy Immunol 2002; 13:402-11.

77 Rettger LF, Horton GD. A comparitive study of the intestinal flora of white rats kept on experimental and ordinary mixed diets. Zentralbl Bakteriol 1914; 73:362-72.

78 Dubos R, Schaedler R, Stephens M. The effect of antibacterial drugs on the fecal flora of mice. J Exp Med 1963; 117:231-43.

79 Gibson GR, Beatty ER, Wang X, Cummings JH. Selective stimulation of bifidobacteria in the human colon by oligofructose and inulin. Gastroenterology 1995; 108:975-82.

80 Fogarty A, Britton J. Nutritional issues and asthma. Curr Opin Pulm Med 2000; 6:86-9.

81 Greene LS. Asthma, oxidant stress, and diet. Nutrition 1999; 15:899-907.

82 Black PN. The prevalence of allergic disease and linoleic acid in the diet. J Allergy Clin Immunol 1999; 103:351-2.

83 La Vecchia C, Decarli A, Pagano R. Vegetable consumption and risk of chronic disease. Epidemiology 1998; 9:208-10.

84 Weiland SK, von Mutius E, Husing A, Asher MI. Intake of trans fatty acids and prevalence of childhood asthma and allergies in Europe. ISAAC Steering Committe. Lancet 1999; 353:2040-1.

85 Strom K, Janzon L, Mattisson I, Rosberg HE, Arborelius M. Asthma but not smoking-related airflow limitation is associated with a high fat diet in men: results from the population study "Men born in 1914", Malmo, Sweden. Monaldi Arch Chest Dis 1996; 51:16-21.

86 Morotomi M, Kawai Y, Mutai M. Intestinal microflora in rats: isolation and characterization of strictly anaerobic bacteria requiring long-chain fatty acids. Appl Environ Microbiol 1976; 31:475-80.

87 Eyssen H, Parmentier G. Biohydrogenation of sterols and fatty acids by the intestinal microflora. Am J Clin Nutr 1974; 27: 1329-40.

88 Eyssen H, Piessens-Denef M, Parmentier G. Role of the cecum in maintaing 5 -steroid- and fatty acid-reducing activity of the rat intestinal microflora. J Nutr 1972; 102:1501-11.

89 Eyssen H. Role of the gut microflora in metabolism of lipids and sterols. Proc Nutr Soc 1973; 32:59-63.

90 Martindale S, McNeill G, Devereux G, Campbell D, Russell G, Seaton A. Antioxidant intake in pregnancy in relation to wheeze and eczema in the first two years of life. Am J Respir Crit Care Med 2005; 171:121-8.

91 Dixon RA. Natural products and plant disease resistance. Nature 2001; 411:843-7.

92 Dubos R. Man Adapting. New Haven: Yale University Press, 1971.

93 Stumbles PA, Upham JW, Holt PG. Airway dendritic cells: co-ordinators of immunological homeostasis and immunity in the respiratory tract. Apmis 2003; 111:741-55.
94 Stagg AJ, Hart AL, Knight SC, Kamm MA. The dendritic cell: its role in intestinal inflammation and relationship with gut bacteria. Gut 2003; 52:1522-9.

95 Dahl ME, Dabbagh K, Liggitt D, Kim S, Lewis DB. Viralinduced $\mathrm{T}$ helper type 1 responses enhance allergic disease by effects on lung dendritic cells. Nat Immunol 2004; 5:337-43.

96 Bohmig GA, Krieger PM, Saemann MD, Wenhardt C, Pohanka E, Zlabinger GJ. N-butyrate downregulates the stimulatory function of peripheral blood-derived antigen-presenting cells: a potential mechanism for modulating T-cell responses by shortchain fatty acids. Immunology 1997; 92:234-43.

97 Saemann MD, Bohmig GA, Osterreicher CH et al. Antiinflammatory effects of sodium butyrate on human monocytes: potent inhibition of IL-12 and up-regulation of IL-10 production. FASEB J 2000; 14:2380-2.

98 Cavaglieri CR, Nishiyama A, Fernandes LC, Curi R, Miles EA, Calder PC. Differential effects of short-chain fatty acids on proliferation and production of pro- and anti-inflammatory cytokines by cultured lymphocytes. Life Sci 2003; 73:1683-90.

99 Andoh A, Bamba T, Sasaki M. Physiological and anti-inflammatory roles of dietary fiber and butyrate in intestinal functions. JPEN J Parenter Enteral Nutr 1999; 23:S70-3.

100 Saemann MD, Bohmig GA, Zlabinger GJ. Short-chain fatty acids: bacterial mediators of a balanced host-microbial relationship in the human gut. Wien Klin Wochenschr 2002; 114:289-300.

101 Noverr MC, Erb-Downward JR, Huffnagle GB. Production of eicosanoids and other oxylipins by pathogenic eukaryotic microbes. Clin Microbiol Rev 2003; 16:517-33.

102 Noverr MC, Phare SM, Toews GB, Coffey MJ, Huffnagle GB. Pathogenic yeasts Cryptococcus neoformans and Candida albicans produce immunomodulatory prostaglandins. Infect Immun 2001; 69:2957-63.

103 Noverr MC, Williams DD, Toews GB, Huffnagle GB. Production of prostaglandins and leukotrienes by pathogenic fungi. Infect Immun 2002; 70:400-02.

104 Robbiani DF, Finch RA, Jager D, Muller WA, Sartorelli AC, Randolph GJ. The leukotriene C(4) transporter MRP1 regulates CCL19 (MIP-3beta, ELC)-dependent mobilization of dendritic cells to lymph nodes. Cell 2000; 103:757-68.

105 Panwala CM, Jones JC, Viney JL. A novel model of inflammatory bowel disease: mice deficient for the multiple drug resistance gene, mdr1a, spontaneously develop colitis. J Immunol 1998; 161: 5733-44.

106 Asseman C, Fowler S, Powrie F. Control of experimental inflammatory bowel disease by regulatory T cells. Am J Respir Crit Care Med 2000; 162:S185-9.

107 Hunt JR, Martinelli R, Adams VC, Rook GA, Brunet LR. Intragastric administration of Mycobacterium vaccae inhibits severe pulmonary allergic inflammation in a mouse model. Clin Exp Allergy 2005; 35:685-90.

108 Kalliomaki M, Salminen S, Poussa T, Arvilommi H, Isolauri E. Probiotics and prevention of atopic disease: 4-year follow-up of a randomised placebo-controlled trial. Lancet 2003; 361: 1869-71.

109 Kalliomaki M, Salminen S, Arvilommi H, Kero P, Koskinen P, Isolauri E. Probiotics in primary prevention of atopic disease: a randomised placebo-controlled trial. Lancet 2001; 357:1076-9.

110 Lodinova-Zadnikova R, Cukrowska B, Tlaskalova-Hogenova H. Oral administration of probiotic Escherichia coli after birth reduces frequency of allergies and repeated infections later in life (after 10 and 20 years). Int Arch Allergy Immunol 2003; 131:209-11.

111 Laiho K, Hoppu U, Ouwehand AC, Salminen S, Isolauri E. Probiotics: on-going research on atopic individuals. Br J Nutr 2002; 88 (Suppl. 1):S19-27. 
112 Isolauri E, Arvola T, Sutas Y, Moilanen E, Salminen S. Probiotics in the management of atopic eczema. Clin Exp Allergy 2000; 30:1604-10.

113 Kirjavainen PV, Salminen SJ, Isolauri E. Probiotic bacteria in the management of atopic disease: underscoring the importance of viability. J Pediatr Gastroenterol Nutr 2003; 36:223-7.

114 Rosenfeldt V, Benfeldt E, Nielsen SD et al. Effect of probiotic Lactobacillus strains in children with atopic dermatitis. J Allergy Clin Immunol 2003; 111:389-95.

115 Majamaa H, Miettinen A, Laine S, Isolauri E. Intestinal inflammation in children with atopic eczema: faecal eosinophil cationic protein and tumour necrosis factor-alpha as non-invasive indicators of food allergy. Clin Exp Allergy 1996; 26:181-7.
116 Majamaa H, Isolauri E. Probiotics: a novel approach in the management of food allergy. J Allergy Clin Immunol 1997; 99: $179-85$.

117 Viljanen M, Savilahti E, Haahtela T et al. Probiotics in the treatment of atopic eczema/dermatitis syndrome in infants: a double-blind placebo-controlled trial. Allergy 2005; 60: 494-500.

118 Mastrandrea F, Coradduzza G, Serio G et al. Probiotics reduce the CD34+hemopoietic precursor cell increased traffic in allergic subjects. Allerg Immunol (Paris) 2004; 36:118-22.

119 Wheeler JG, Shema SJ, Bogle ML et al. Immune and clinical impact of Lactobacillus acidophilus on asthma. Ann Allergy Asthma Immunol 1997; 79:229-33. 